\section{Weathering and glacial cycles}

SIR - Lovelock and Kump ${ }^{1}$ present a simple model to explain how the terrestrial and marine biota might affect glacial-interglacial climate variation. In their general scheme, the optimal conditions for $\mathrm{CO}_{2}$ uptake by biologically mediated weathering are the cool glacial periods. They thus suggest that during the glacial periods land vegetation mediates increased rates of chemical weathering uptake of $\mathrm{CO}_{2}$ (relative to the interglacials), which could favour low $\mathrm{CO}_{2}$ levels and help to stabilize glacial climates.

However, given that chemical weathering is strongly favoured by warm, moist conditions $^{2}$, there seems reason to believe that global weathering rates were higher during interglacial periods than during glacial periods. Generally, glacial maxima are very dry and cold on a global scale ${ }^{3,4}$, and this would tend strongly to suppress weathering rates relative to the much warmer and moister interglacials. The accumulation of chemically unstable minerals in surface sediments during glacials should furthermore tend to promote a 'burst' of chemical weathering during the interglacial conditions that follow. Even though some parts of glacial phases do appear fairly moist on a global scale, at these times the cooler conditions should suppress weathering relative to the interglacial phase $\mathrm{e}^{5}$. Thus there seems no strong basis for assuming that global $\mathrm{CO}_{2}$ uptake by terrestrial weathering should be greater during glacial phases.

It seems that the conclusion of Lovelock and Kump ${ }^{1}$, that the action of land vegetation as a catalyst for the $\mathrm{CO}_{2}$ weathering sink is to 'pull' the Earth's climate system back down towards glacial levels, may be unjustified. Instead, variation in weathering rates seems likely to act as a damping agent on both $\mathrm{CO}_{2}$ and climate on the glacial-interglacial timescale (dragging down $\mathrm{CO}_{2}$ levels more strongly during interglacials, and relatively weakly during glacials), against a background of large oceanically driven $\mathrm{CO}_{2}$ changes.

Changes in bulk terrestrial carbon storage in land ecosystems may have a greater influcnce on glacial-interglacial fluctuations in $\mathrm{CO}_{2}$ levels. There are good reasons for thinking that this too would have acted as a negative feedback on $\mathrm{CO}_{2}$ fluctuations between glacial and interglacial conditions ${ }^{3}$, paralleling the effects of weathering.

\section{Jonathan Adams}

School of Geography,

University of Oxford,

1 Mansfield Road,

Oxford OX1 3TB, UK
LOVELOCK AND KUMP REPLY - A conceptual paper such as ours ${ }^{1}$ is undoubtedly subject to criticism, and, it was our hope that it would stimulate discussion. However, Adams' criticisms ${ }^{6}$ are based on an obvious misreading of our paper. $\mathrm{He}$ claims that we propose "optimal conditions for $\mathrm{CO}_{2}$ uptake by biologically mediated weathering are the cool glacial periods." This is a misstatement of our basic premise. In several places, including our Fig. 1, we point out that the ecological optimum for land plants is probably near a global average of $18^{\circ} \mathrm{C}$, certainly not the "cool glacial" state, but rather a state even warmer than today's.

Perhaps Adams has misunderstood the nature of the feedback processes described in our paper. We argue that under glacial conditions both the marine algae - cloud albedo and the plant-mediated $\mathrm{CO}_{2}$ feedbacks are negative: increased temperatures cause increased albedo and increased $\mathrm{CO}_{2}$ consumption rates, both of which tend to reduce global temperatures, damping the initial perturbation. In this regard our paper is in agreement with Adams' claim that glacial weathering rates were slower, although as we show below, some of the explanatory factors he invokes actually tend to argue for faster interglacial rates. Our feedback mechanism does tend to "pull the Earth's climate system back toward glacial level", but the "pull" is primarily from the marine algae - cloud albedo feedback loop not the land plant $-\mathrm{CO}_{2}$ loop. Indeed, a simple numerical model (our Fig. 2) demonstrates that when the marine loop fails, the land plant loop regulates at global temperatures warmer than today's.

Many factors besides biological enhancement influence global chemical weathering rates, as Adams points out. However, in a recent analysis of the effect of changes in continental-scale hydrology and rock exposure on chemical weathering during glaciations, Gibbs and L. R. K. ${ }^{6}$ found that the rate of glacial chemical erosion was somewhat greater than today's, based on climate model results and a consideration of the weatherability of materials exposed on the tropical continental shelves by sea-level fall. Even if interglacial rates are higher, it is highly unlikely that they are "several times higher", as Adams contends. The depth in the ocean below which dissolution of carbonate sediments is complete (the carbonate compensation depth or CCD) is sensitive to the rate of alkalinity supply to the ocean from continental weathering ${ }^{7}$. The glacial sediment record of $\mathrm{CCD}$ variations ${ }^{8}$ seems to allow only small changes in chemical weathering on the timescale of glacial/interglacial fluctuations ${ }^{6}$. We agree that the production of highly weatherable materials (till and loess) during glaciations might produce a "burst of chemical weathering during the interglacial conditions that follow", and may be responsible for the anomalous preservation of pelagic carbonate sediments during deglaciations (ref. 9 and $\mathbf{J}$. W. Farrell, personal communication).

We apologize for not explicitly recognizing Adams' impressive work on glacial, terrestrial ecosystems in our paper. Certainly one can consider changes in the terrestrial biomass as part of the sink we describe in our abstract as the "fixation of atmospheric $\mathrm{CO}_{2}$ ". We admit that our thoughts were focused on the longer-term sink associated with chemical weathering, and that on shorter $\left(10^{4} \mathrm{yr}\right)$ timescales changes in the terrestrial biomass have the capacity to modulate atmospheric $\mathrm{CO}_{2}$ variations. We look forward to further stimulating discussions of the admittedly controversial ideas presented in our paper.

James E. Lovelock

Coombe Mill,

St Giles on the Heath,

Launceston PL 15 9RY, UK

Lee R. Kump

Earth System Science Center

and Department of Geosciences,

The Pennsylvania State

University, University Park,

Pennsylvania 16802, USA

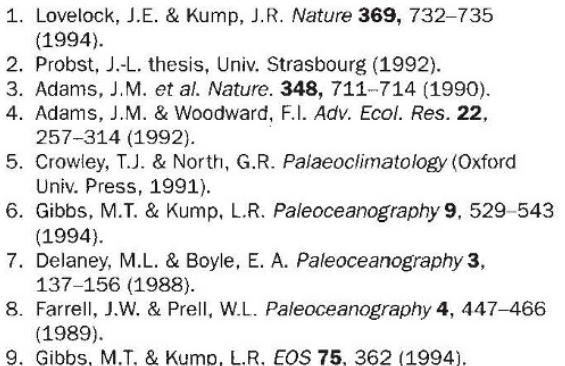

\section{Dorsoventral axis inversion}

SIR - Arendt and Nübler-Jung ${ }^{1}$ highlight a problem that molecular biologists have encountered when comparing the spatial expression patterns of key developmental control genes between insects and vertebrates. The axial patterns (for example, of Hox genes) are beautifully conserved, but patterns along the dorsoventral axis are inverted in some instances. Arendt and Nübler-Jung cite data on decapentaplegic, a gene involved in dorsoventral patterning, and its vertebrate homologue, $B M P-4$. Expression is dorsal in Drosophila and ventral in vertebrates, though there are complications: other members of this gene family in vertebrates are expressed in both the dorsal and ventral parts of the nerve cord, which is itself a dorsal structure ${ }^{2}$. Another example is wingless, which has ventral expression in various Drosophila body parts $^{3}$. Its vertebrate counterparts are the 